ADLFI. Archéologie de la France -

INFORMATIONS

Informations

une revue Gallia

Midi-Pyrénées | 1989

\title{
Causse de Gramat
}

\section{(2) OpenEdition \\ Journals}

Édition électronique

URL : http://journals.openedition.org/adlfi/10912

ISSN : 2114-0502

Éditeur

Ministère de la culture

Référence électronique

"Causse de Gramat », ADLFI. Archéologie de la France - Informations [En ligne], Midi-Pyrénées, mis en ligne le 01 mars 1997, consulté le 30 avril 2019. URL : http://journals.openedition.org/adlfi/10912

Ce document a été généré automatiquement le 30 avril 2019

(c) Ministère de la Culture et de la Communication, CNRS 


\section{Causse de Gramat}

Date de l'opération : 1989 - 1991 (PR)

Inventeur(s) : Maynard Guy

1 Cette opération réalisée selon les mêmes critères que ceux appliqués dans le nord du Quercy, par Jean-Pierre Girault, est à l'origine de nombreuses observations dépendant soit d'un contexte géologique particulier, soit de « remises en cultures » qui occasionnent de multiples destructions. L'intérêt d'une recherche extensive, diachronique, réside dans le fait qu'elle associe parfois la découverte inédite d'importantes nécropoles tumulaires comme à Rocamadour et En Caminou (trente-sept tertres), à des dolmens pourtant bien connus et inventoriés.

2 Un autre ensemble a été repéré aux Bascoulés au voisinage de deux dolmens inédits dont un à vestibule. C'est un gisement mégalithique de même nature qui est encore signalé à Gramat, La Bournerie.

3 À la suite de résultats négatifs concernant l'éventuelle nécropole d'Estouilles-Vieilles (cf. infra), on peut considérer l'ensemble des tertres repérés comme systématiquement anthropiques. Ainsi, près de $40 \%$ des tumulus inventoriés sur les communes d'Issendolus et de Gramat incitent, d'une manière générale, à la prudence dans les interprétations. En revanche, la présence de tegulae et d'imbrices, de céramiques sigillées et communes à Marinhac-Lentour, Bonnefont dans deux petites levées de terre indiquent la présence d'un établissement gallo-romain tout proche.

4 Les falaises bordant l'Ouysse et la Dordogne ont été systématiquement visitées : dix-neuf grottes ont été inventoriées dont trois ont révélé une occupation humaine. À Lacave, la grotte de Bourgnou a livré du matériel magdalénien et celle du Pech de la Treille des éléments de faunes associés à du mobilier d'allure protohistorique.

$5 \quad$ C'est un total de trente-six dolmens dont sept inédits, deux coffres, deux menhirs, deux cent quarante-trois tumulus ou pseudo-tumulus, une vingtaine de gisements et trentedeux grottes qui ont pu être recensés. 
INDEX

peuple Magdalénien

Index chronologique : âge du Fer, Antiquité romaine, Néolithique, Paléolithique supérieur operation Prospection (PR) 